\title{
Is It Time to Take a Pass on the Increased Number of Passes in EUS-FNA?
}

\author{
Shantel Hébert-Magee $\cdot$ Robert H. Hawes • \\ Shyam Varadarajulu
}

Published online: 8 August 2013

(c) Springer Science+Business Media New York 2013

Despite the extensive use of endoscopic ultrasound-guided fine-needle aspiration (EUS-FNA), there still exists a wide variation in the number of samples required to ensure acquisition of diagnostic material from pancreatic lesions. Although multiple passes can be performed during EUSFNA, prolonging the procedure likely increases risk, decreases procedural efficiency, and increases the probability of samples being tainted with blood. It has been 21 years since EUS-FNA was used to obtain pancreatic tissue for cytologic analysis [1, 2], 16 years since the publication of the first reports evaluating the clinical impact and staging of pancreatic lesions sampled by EUSFNA [3], and 14 years since the publication of the initial reports of the evaluation of the number of passes needed to obtain a diagnostic yield and the significance of on-site cytopathology during the procedure [4-7]. During this time, the focus has been on determining the necessity of on-site cytopathologic evaluation, the optimal number of needle passes, and the most effective needle type used for tissue acquisition. Despite numerous studies addressing these issues, many endoscopists are still perplexed about the nature of the best practices needed to ensure optimal results, in particular with regard to the need for on-site cytopathology for skilled and experienced endosonographers practicing at a high-volume center. To date, multiple meta-analyses have confirmed the diagnostic accuracy, cost-effectiveness, accuracy, and safety of EUS-FNA for solid pancreatic lesions [8-12]. Moreover, structured literature reviews have concluded that rapid on-site evaluation (ROSE) improves diagnostic accuracy [8, 9].

S. Hébert-Magee $\cdot$ R. H. Hawes · S. Varadarajulu $(\bowtie)$ Center for Interventional Endoscopy, Florida Hospital, 601 East Rollins Street, Orlando, FL 32803, USA

e-mail: svaradarajulu@yahoo.com
Notwithstanding these considerable successes, ongoing refinements to EUS-FNA continue to be explored.

Regardless of the likelihood that increasing numbers of passes raises the risk of needle failure, tissue injury, postprocedural complications, and medical expenses, the endosonographer is caught between the need to provide adequate tissue needed to optimize diagnostic yield weighed against the cost and risk of making additional passes. Failed EUS-FNA often engenders additional risk and expense due to the need to repeat EUS or to obtain tissue with radiologic or surgical guidance. Moreover, as treatment options for pancreatic cancer advance, rendering an onsite diagnosis alone may not be adequate, since additional tissue may be required to perform ancillary studies and molecular mapping. Nevertheless, ROSE may not be financially viable due to excess time commitment, limited resources, relatively low reimbursements, and acceptable adequacy rates achieved by more experienced endosonographers. In order to have a sustainable EUS practice with optimal clinical outcomes, it may be beneficial to provide some degree of ROSE training for endosonographers incorporating the "fanning" FNA technique combined with an algorithmic approach to needle selection [13-15].

In this issue of Digestive Diseases and Sciences, Schmidt et al. [16] examined current practices of lesion sampling, weighing diagnostic accuracy against the probability of adverse events in the presence and absence of ROSE. The authors provide empirical data regarding the diagnostic yield and performance characteristics of EUS-FNA of solid pancreatic lesions using mathematical modeling to determine the likelihood of adverse events with a fixed number of passes (no-ROSE) versus a variable number of passes (ROSE) while controlling for other variables. Schmidt and colleagues used a discrete-event simulation model to conclude that ROSE reduces the number of passes, thereby reducing the 
probability that adverse events will occur. The ability of these investigators to create a simulation model that adjusts for confounding variables (e.g., experience of the center, variability of patient characteristics, lesion size, and location) is quite convincing, even to those who inherently doubt the need for ROSE. Hence, the principal importance of the Schmidt et al. study is the use of unambiguous, unbiased, computational analysis in the formulation of the authors' conclusions.

As a pathologist and proponent of on-site evaluation (S.H.M.), I recognize the value of being present in the endoscopy suite during the procedure. Being on site enabled me to obtain clinical information that may not be available on the requisition form, evaluate the aspirated material, render a preliminary diagnosis when possible, triage the specimen appropriately, provide the endosonographer with procedure-altering information, and provide information that could expedite clinical management. In addition to the substantial time commitment, other objections to ROSE raised by pathologists may be due to a lack of specific training or experience with the specialized methods used. Unlike other EUS-FNA target tissues, the pancreas presents particular diagnostic challenges, especially for the inexperienced assessor, that can mostly be overcome with teams experienced with ROSE $[17,18]$.

The data presented by Schmidt et al. suggest that ROSE is mostly useful when the FNA procedure is being performed by a novice endosonographer, the lesion is technically challenging, or if the sampling technique is poor. These findings, combined with the published data, provide a compelling case to provide for ROSE universally in an effort to improve diagnostic accuracy while increasing patient safety.

While it may be impractical for onsite cytology assistance to be made available at every center, onsite evaluation of cytologic samples is definitely feasible, in light of the basic training in EUS-cytology increasingly provided to advanced endoscopy fellows [19] combined with the growing number of procedures being performed, the rising demand for EUS-FNA of solid pancreatic lesions, and the expectation of not only providing a diagnosis but also determining the need for ancillary studies and molecular characterization. In short, the independent endosonographer can no longer solely rely on a fixed number of passes to provide diagnostic sufficiency in many cases, but should have access to ROSE or be trained in EUS cytopathology in order to achieve optimal clinical outcomes.

\section{References}

1. Wiersema MJ, Hawes RH, Tao LC, et al. Endoscopic ultrasonography as an adjunct to fine needle aspiration cytology of the upper and lower gastrointestinal tract. Gastrointest Endosc. 1992;38:35-39.

2. Vilmann P, Jacobsen GK, Henriksen FW, et al. Endoscopic ultrasonography with guided fine needle aspiration in pancreatic disease. Gastrointest Endosc. 1992;38:172-173.

3. Chang KJ, Nguyen P, Erickson R. The clinical utility of endoscopic ultrasound-guided fine-needle aspiration in the diagnosis and staging of pancreatic carcinoma. Gastrointest Endosc. 1997;45:387-393.

4. Klapman JB, Logrono R, Dye CE, et al. Clinical impact of on-site cytopathology interpretation on endoscopic ultrasound-guided fine needle aspiration. Am J Gastroenterol. 2003;98:1289-1294.

5. Chhieng DC, Jhala D, Jhala N, et al. Endoscopic ultrasoundguided fine-needle aspiration biopsy: a study of 103 cases. Cancer. 2002;96:232-239.

6. Eloubeidi MA, Jhala D, Chhieng DC, et al. Yield of endoscopic ultrasound-guided fine-needle aspiration biopsy in patients with suspected pancreatic carcinoma. Cancer. 2003;99:285-292.

7. Erickson RA, Sayage-Rabie L, Beissner RS. Factors predicting the number of EUS-guided fine-needle passes for diagnosis of pancreatic malignancies. Gastrointest Endosc. 2000;51:184-190.

8. Chen J, Yang R, Lu Y, et al. Diagnostic accuracy of endoscopic ultrasound-guided fine-needle aspiration for solid pancreatic lesion: a systematic review. J Cancer Res Clin Oncol. 2012;138: 1433-1441.

9. Hébert-Magee S, Bae S, Varadarajulu S, et al. The presence of a cytopathologist increases the diagnostic accuracy of endoscopic ultrasound-guided fine needle aspiration cytology for pancreatic adenocarcinoma: a meta-analysis. Cytopathology. 2013;24:159-171.

10. Puli SR, Bechtold ML, Buxbaum JL, et al. How good is endoscopic ultrasound-guided fine-needle aspiration in diagnosing the correct etiology for a solid pancreatic mass? A meta-analysis and systematic review. Pancreas. 2013;42:20-26.

11. Affolter KE, Schmidt RL, Matynia AP, et al. Needle size has only a limited effect on outcomes in EUS-guided fine needle aspiration: a systematic review and meta-analysis. Dig Dis Sci. 2013;58:1026-1034.

12. Hewitt MJ, McPhail MJ, Possamai L, et al. EUS-guided FNA for diagnosis of solid pancreatic neoplasms: a meta-analysis. Gastrointest Endosc. 2012;75:319-331.

13. Hayashi T, Ishiwatari H, Yoshida M, et al. Rapid on-site evaluation by endosonographer during endoscopic ultrasound-guided fine needle aspiration for pancreatic solid masses. J Gastroenterol Hepatol. 2013;28:656-663.

14. Varadarajulu S, Fockens P, Hawes RH. Best practices in endoscopic ultrasound-guided fine-needle aspiration. Clin Gastroenterol Hepatol. 2012;10:697-703.

15. Bang JY, Magee SH, Ramesh J, et al. Randomized trial comparing fanning with standard technique for endoscopic ultrasound-guided fine-needle aspiration of solid pancreatic mass lesions. Endoscopy. 2013;45:445-450.

16. Schmidt RL, Walker BS, Howard K et al. Rapid on-site evaluation reduces needle passes in endoscopic ultrasound-guided fineneedle aspiration for solid pancreatic lesions: a risk-benefit analysis. Dig Dis Sci. (Epub ahead of print). doi:10.1007/s10620013-2750-6.

17. Eltoum IA, Chhieng DC, Jhala D, et al. Cumulative sum procedure in evaluation of EUS-guided FNA cytology: the learning curve and diagnostic performance beyond sensitivity and specificity. Cytopathology. 2007;18:143-150.

18. Eloubeidi MA, Tamhane A. EUS-guided FNA of solid pancreatic masses: a learning curve with 300 consecutive procedures. Gastrointest Endosc. 2005;61:700-708.

19. Varadarajulu S, Jhala NC. Cytopathology: a dying art or something that a gastroenterologist should know? Gastrointest Endosc. 2012;76:397-399. 